\title{
International Mining Students' Perceptions of Online and Classroom Interaction (A Case Study of Kuzbass University)
}

\author{
Irina Saveleva ${ }^{1,{ }^{*}, \text { Svetlana Kolomiets }}{ }^{1}$, Elena Medvedeva $^{2}$, and Anna Saveleva ${ }^{3}$ \\ ${ }^{1}$ Kemerovo State University, Institute of Philology, Foreign languages and Media communication, \\ 650000 Kemerovo, 6 Krasnaya, Russian Federation \\ ${ }^{2}$ Kemerovo State Medical University, 650056 Kemerovo, 22 Voroshilova, Russian Federation \\ ${ }^{3}$ Kemerovo State University, Institute of Psychology and Social Sciences, 650000 Kemerovo, 6 \\ Krasnaya, Russian Federation
}

\begin{abstract}
Distance education, which opens up a new era of digitalization and sustainable development of the society, is gaining momentum today. However, a vast array of challenges comes up when online interaction in which student and teacher are engaged fully replaces communication in traditional classroom. This paper seeks to contribute to the advantages of face-to-face learning, as perceived by the international mining students. The data have been collected from the open format questionnaires fulfilled by the overseas students who came to study mining engineering at the university of Kuzbass. The qualitative content analysis and, subsequently, the researchers' interpretation of the data reveals that students observe various features related to student teacher interaction in online and offline settings. Notably, these features correlate to the variables constituting the core of pedagogical interaction: performance, motivation, communication, cognition, emotions, physical state, and temporal dimension.
\end{abstract}

\section{Introduction}

Challenges faced by the society are vast and multifaceted. According to Global Sustainable Report 2019, one of the urgent issues proclaimed in the 2030 Agenda is the access to highquality education $[1 ; 2]$.

The COVID 19 pandemic has exacerbated the problems in education that have arisen in connection with integration processes. It has forced teachers and students to switch to distance learning within a short time period. The positive understanding of learning outcomes was due to mass involvement in new attractive platforms, which, above all, increased motivation and facilitated learning. No shortcomings were noticed at the first stage of conducting online interaction on platforms such as Zoom, Discord, Google Classroom, Microsoft Teams, and others.

\footnotetext{
*Corresponding author: saviren1973@mail.ru
} 
Indeed, some interactants expressed their admiration for the degree of freedom they were satisfied with when they joined university online lectures and seminars from their homes. In this context, the diverse interactions that take place over the Internet have led to increased learning and enhanced motivation and involvement of students in the process of obtaining a variety of qualifications, mining engineering, in particular [3].

At the subsequent stage of Internet-mediated communication, all participants of the educational interaction equally felt the lack of live interaction. Educational agents faced a problem: whether it is possible to teach professional skills and qualitatively form competencies in students of applied and engineering specialties through online platforms, that is, without personal communication and interaction of students with professionals, in the absence of "hands-on", practical experience.

Taking into account the fact that the young generation who entered universities has highly developed computer skills and a positively assessed level of technological competence teachers express their confidence in the convenience of online learning and the effectiveness of online interaction [4].

Along with this opinion, the researchers make a number of critical comments [5]. It is noted, that the digitalization of education should be combined with contact training and the possibility of communication in traditional university classrooms. The lack of live contact with the teacher, direct interaction between the teacher and the student is recognized as an increasingly important problem. Moreover, the interest in building teacher student relationship within the classroom is expressed by the students themselves, who spent part of their professional training as future engineers at the initial stage in the virtual classroom.

\section{Theory and method}

Teacher student interaction is defined as "a unit in a planned curricular sequence, an instance of a teaching method in operation, a patterned social activity, and an encounter between human personalities" [6, p. 225]. Per se, it can be viewed from different perspectives: as an essential pedagogical problem, a communicative situation that arises in the classroom, and as an episode of social life, each of the participants of which assumes a set of institutional roles.

\subsection{Interaction as a pedagogical issue}

The teacher-student relationship is crucial to student success. Most studies on classroom interaction in educational institutions have sought to contribute to systematic patterns of teacher behaviour. As J. Green and C. Dixon note, first researchers of interaction entered classrooms to determine pedagogical behaviour, primarily realized through conversation. They go on to write, "Issues of interest included democratic and authoritarian teaching practices and direct and indirect learning, with little direct emphasis on what was learned" $[7, \mathrm{p} .3]$.

Interaction in the educational aspect is seen as a combination of communicative exchanges in which one individual addresses another individual or group of individuals and receives at least one response in return. Interaction is an essential property of the pedagogical process. In the classroom, as a rule, there are three types of interaction:

- interaction with the material (the student interacts with the task, for example, with the text);

- interaction with peers (the student interacts with other students);

- interaction with the teacher (the student interacts with the teacher) [8].

Thus, these focuses led to the development of the IRF model, originally proposed by Sinclair and Coulthard (1975), which turned out to be regularly applied by most teachers, 
regardless of their teaching style and set of teaching methods. It is created by the three movements of interaction:

(I) - Initiating the action of the teacher

(R) - Reciprocal movement of the student (response)

(F) - Teacher's Follow-up [9].

This is considered as the least possible type of interaction that takes place in the class. In most cases, this pattern consists of a question initiated by the teacher, an answer given by the student, and then feedback provided by the teacher.

As mentioned earlier, the role of the teacher should not be underestimated [10]. In this regard, one of the most important elements of the higher education system and universities are university teachers, who play a crucial role in achieving the goals and objectives of higher education in quantitative and qualitative terms. Therefore, studying their competence and performance in various dimensions, especially in the area of their interaction with students, in order to motivate them through favourable classroom climate, can play an important role in improving the quality of students' learning and their educational achievements.

\subsection{Interaction as a communicative issue}

In communicatively approached teaching and learning process there are factors that mediate information delivery schemes. Firstly, these are ways the teachers organize instruction within their classrooms. Good communication skills ensure that each teacher gets the best from the students. Thus, in the study of G. Amadi and A. K. Paul, it is shown what role communication between a teacher and a student plays in the motivation and academic performance of the latter. The researchers emphasize the importance of effective communication in classroom instruction, especially in this 21 st-century system of teaching and learning [11, p. 1102]. In their work, the ten ways, which significantly invigorate students' achievement, stand out:

1. Show a sincere enthusiasm or humour

2. Build friendship

3. Make learners the focus

4. Ensure that there is a trust

5. Create an atmosphere of interdependence

6. Probe into learners' intellectual aptitude at the onset of a class

7. Make learners feel challenged

8. Be a master of the subject matter

9. Understand different learning styles and be generic

10. Be accommodative and tolerate students' mistakes [11].

Having analysed teacher-student relationships in communicative aspect $\mathrm{R}$. West suggested three categories of positive (teacher helping, recognition, enjoyment via activity) and five categories of negative (embarrassment, unjustifiable discipline, unwanted aggression, inappropriate affection, unrealistic expectation) communicative experiences [12].

In language teaching the problem of using adequate communication strategies rises when it comes to effective transactions between a teacher and students, and between the students themselves. Communication strategies all together form communication competency. Numerous studies focused on identifying and classifying communication strategies. For instance, in the work conducted by I. A. Krishnan et al., they report about seven communication strategies utilized by the students [13]. 
Generally, it has been shown that growing proficiency in language use and teacher's communicative skills foster student performance in class and ultimately their excellence in the whole course.

\subsection{Interaction as a social issue}

It is undeniable that knowledge is acquired through communication. Alongside with this, each of us is a social creature and is engaged in constant interactions with the other members of the society. This is the reason why in educational context the set of relationships, which take place between students and a teacher, is often studied within the framework of social interaction theory. Learning is initially "a social function" as it takes place through interactions, as put forth by L. Vygotsky [14].

This contributes to the assumption that in teaching and learning environments both communication and interaction occur. As such, they have a great impact on the learning outcomes. The micro patterns of these relationships are regarded as social interactions since they provide the senders and the recipients of information (as in the communication model) with more than just factual content. The pursue of educational goals puts the teachers and the students into situations of social interdependence, firstly, because they form a community with certain kind of an atmosphere and the hierarchy of social roles, secondly, because they all obey norms and accept conventionalized patterns of social behaviour.

The process of knowledge transfer and skill formation is impossible without social interaction. Propelled into the Russian-speaking environment, a foreign student has to be acquainted with the academic environment and its socio-cultural norms. The educational team, which trains representatives of different ethnic groups - is an academic community, which develops its own relations and the symbolism of interaction. A sense of inclusion in the group and in the student-teacher relationship gives the student self-confidence and an understanding of himself as an equal participant in the educational process.

\subsection{Research procedure}

The data collection was conducted through open-ended questions offered to the group of the second year students from India $(n=24)$. The questions aimed at examining international students' attitude towards teacher-student interaction as conducted online and face-to face.

At the preliminary stage, they were offered to estimate the benefits and drawbacks of online learning as compared to traditional instruction in class. All the participants completed the questionnaires on a voluntary basis.

At the second stage of the study, they gave their answers to the questions that concerned their overall assessment and attitude to distant instruction that temporarily replaced face-toface interaction with the teacher and their peers. Then their answers were analysed on the qualitative basis. The data were interpreted by means of discourse analytical methods as well as by applying the service that conducts SEO analysis of the textual corpus [15]. Ultimately, the key concepts were taken as variables, and were grouped into seven categories relating to basic components of teacher-student interaction.

\section{Results and discussion}

The responses given by the participants allowed us to observe some of the most important aspects of interactivity occurring in the classroom.

Focus on cognitive strategies. Students reported that online interaction was challenging for them as they failed to understand many important topics that show that the cognition 
factor is crucial. They wrote, "...as we get practical work and it's easy to understand problem". For them, the concept of understanding played a key role in the process of moving their education to the next level. Seventeen respondents $(71 \%)$ consented that knowledge is better absorbed in face-to-face interaction.

Focus on emotional condition and performance. According to their texts, they also view emotions as an important aspect of classroom interaction. Thus, we were able to differentiate the affective component. Ten students (42\%) indicate a deterioration in their emotional state during the distance learning period. As one of the students admits, "I get so frustrated and irritated". The respondent experienced exactly these emotions when he realized his failure. Indeed, he goes on to say, "...as time passed I saw major decline in my performance". Thus, this verbatim data reveals another aspect of the perception of interaction in the classroom - performance. Some students felt that they could not handle the curriculum in the online settings (32\%).

Focus on communication. The next factor formulated by the students in their positions was their communication skills. Eleven out of twenty-four respondents (46\%) indicated difficulties in communication. In particular, the students identified such parameters as the ability to directly ask questions to the teacher and directly respond to his speech. In regular foreign language classes, students are usually attracted by the opportunity to talk with the teacher, to be engaged in the practical tasks that are impossible in online interaction. They regard the distant form of communication as more one-sided, resembling lecture classes. That is, the teacher's speech in the distant lesson dominates the speech of the students. The opportunity to express your point of view is also seen as a more accessible form of communication in contact training. In their responses, we find, "The teacher creates environment of education near us"; "We talk with the teacher...;"We can have direct questions". These nuances indicate the desire of students to participate more actively in communication than when performing tasks online. For instance, one of them wrote, "...online I study more theory".

Focus on physical condition and motivation. Importantly, four students (17\%) noticed that their physical condition during online classes was not satisfactory. They reported that they had vision problems, for instance, one admitted, "My eyes strain". Indeed, they went on to say, that they are unable to use gadgets continuously. One of them was complaining, "I just can't work with the phone all the time".

Focus on motivation. Along with this, the students point out another significant issue. They noticed that staying in homes (in the comfort zone) did not have a positive effect on their motivation. Instead, this factor reduces efficiency and resourcefulness, and the participants perceived this as follows: "I feel less energetic towards study because of lack of face to face interaction"; "...students are less active"; "...online class makes students lazy".

Focus on time. Finally, several respondents noted that deadline requirements could also be one of the important issues when it came to online interaction replacing face-to-face training. Two of the respondents $(8 \%)$ point to the chronometric component saying, "Time is limited online unlike at regular classes".

Qualitative data analysis allows us to present the results in the following chart with each selected component estimated by means of SEO (semantic) analysis of key tokens. This has been performed using the online service Miratext (Table 1). 
Table 1. The results of SEO analysis and key word distribution by interaction variables.

\begin{tabular}{|c|c|c|}
\hline Variable & Key word & Frequency \\
\hline $\begin{array}{l}\text { Cognition } \\
\text { (explanation, } \\
\text { ability to understand, } \\
\text { acquisition) }\end{array}$ & $\begin{array}{l}\text { Understand } \\
\text { Topic } \\
\text { Attention } \\
\text { Know }\end{array}$ & $\begin{array}{l}1.73 \\
1.44 \\
0.58 \\
0.58\end{array}$ \\
\hline $\begin{array}{c}\text { Affection } \\
\text { (emotions, smiles, } \\
\text { facial expressions, } \\
\text { gestures) }\end{array}$ & $\begin{array}{c}\text { Feel } \\
\text { Bad } \\
\text { Face interaction }\end{array}$ & $\begin{array}{l}0.86 \\
0.58 \\
0.20\end{array}$ \\
\hline $\begin{array}{c}\text { Motivation } \\
\text { (laziness, energy, } \\
\text { inspiration) }\end{array}$ & $\begin{array}{l}\text { Active } \\
\text { Worse } \\
\text { Lazy } \\
\text { Energy }\end{array}$ & $\begin{array}{l}0.50 \\
0.49 \\
0.49 \\
0.40\end{array}$ \\
\hline $\begin{array}{l}\text { Performance } \\
\text { (error correction and } \\
\text { progress estimation) }\end{array}$ & $\begin{array}{c}\text { Easy } \\
\text { Effectively }\end{array}$ & $\begin{array}{l}0.58 \\
0.58\end{array}$ \\
\hline $\begin{array}{l}\text { Communication } \\
\text { (language use, } \\
\text { rapport, clarity, } \\
\text { interpersonal } \\
\text { contact) }\end{array}$ & $\begin{array}{c}\text { Communicate } \\
\text { Class } \\
\text { Talk } \\
\text { Questions } \\
\text { Ask }\end{array}$ & $\begin{array}{l}0.86 \\
0.86 \\
0.86 \\
0.60 \\
0.60\end{array}$ \\
\hline $\begin{array}{c}\text { Physical state } \\
\text { (health conditions) }\end{array}$ & $\begin{array}{c}\text { Comfort zone } \\
\text { Can't work } \\
\text { Strain }\end{array}$ & $\begin{array}{l}0.82 \\
0.58 \\
0.40\end{array}$ \\
\hline $\begin{array}{l}\text { Time perception } \\
\text { (time requirements) }\end{array}$ & $\begin{array}{l}\text { Requirement } \\
\text { Limit(ed) } \\
\text { Less }\end{array}$ & $\begin{array}{l}0.30 \\
0.25 \\
0.20\end{array}$ \\
\hline
\end{tabular}

In accordance with the results of the analysis of students' responses to the frequency of keywords, it is possible to identify the variables that receive the most attention from respondents when perceiving interaction. These are the components of cognition and communication, since the greatest frequency is observed in the use of words 'understand' (1.73), 'topic' (1.44), 'communicate' (0.86), 'class' (0.86), 'talk' (0.86). In addition, the frequency rates of the key words 'feel' $(0.86)$, and 'comfort zone' $(0.82)$ indicate that the respondents are also focused on their emotional and physical state.

\section{Conclusion}

As a result, we can conclude that foreign students perceive teacher student interaction ambiguously. Half of the respondents tend to neutralize the transfer of interaction to the virtual environment. At the same time, $71 \%$ of respondents note one or another negative fact that characterizes the lack of direct interaction between the teacher and the student. 
These shortcomings indicate seven main components of the learning process: cognition, emotions, motivation, academic performance, communication, physical condition, and learning time frame. It is also possible to draw an intermediate conclusion about the need to review the methods of inclusive learning in online interaction. Today, one of the main disadvantages of distance learning is the disparity between the theoretical and practical knowledge acquired by students in online courses. They clearly express a desire to be more actively involved in practice-oriented mining training. If it concerns language disciplines, then teachers need to master interactive methods of learning, where students would have more opportunities for communication and for realizing their needs in active, productive interaction with both the teacher and fellow students. Only then will online training meet the participant's social and communication needs.

\section{Acknowledgement}

The reported study was funded by RFBR, project number 19-013-00805.

\section{References}

1. Development Report 2019: The Future is Now - Science for Achieving Sustainable Development, (United Nations, New York, 2019)

2. S. Zhironkin, M. Gasanov, G. Barysheva, E. Gasanov, O. Zhironkina, G. Kayachev, E3S Web Conf. 21, 04002 (2017)

3. D. R. Abraham, Student-Teacher Interaction in Online Learning Environments (IGI Global, New York, 2015)

4. I. Saveleva, O. Greenwald, S. Kolomiets, E. Medvedeva, E3S Web Conf. 21, 04024 (2017)

5. Z.P. Nkabinde, Research Anthology on Developing Effective Online Learning Courses, Ed. by IRMA, 1602-1616 (IGI Global, New York, 2021)

6. N.S. Prabhu, TESOL Quarterly, 26, 2, 225-241 (1992).

7. J. Green, C. Dixon, Encyclopedia of Language and Education (Springer Science+Business Media LLC, New York, 2008)

8. C. Alvarez-Alvarez, L. Sanchez-Ruiz, A. Ruthven, J.M. Del Corte, JEICOM, 1(1), 919 (2019)

9. M.D. Ramírez-Verdugo, L. López Castellano, Interdisciplinary Approaches Toward Enhancing Teacher Education (IGI Global, New York, 2021)

10. S. Jafari, A. Asgari, Integration of education, 24(1), 62-74 (2020)

11. G. Amadi, and A. Kufre Paul, American Journal of Educational Research, 5(10), 11021107 (2017)

12. R. West, Communication Reports, 7(2), 109-118 (1994)

13. I. A. Krishnan, S. J. Ramalingam, H. S. Ching, E. Maruthai, Journal of Language and Communication, 5, 2, 151-159 (2018)

14. P. McGee, J. Voeller, Student-Teacher Interaction in Online Learning Environments (IGI Global, New York, 2015)

15. Miratext, Full Semantic Analysis. URL: https://miratext.ru/seo_analiz_text 